\title{
Incidence, Risk Factors and Short Term Outcome of Acute Kidney Injury among Patients with Acute Coronary Syndrome
}

\author{
Md. Kabir Hossain 1*, Muhammad Rafiqul Alam1, Asia Khanam1, A. K. M. Shahidur Rahman1, \\ Rafi Nazrul Islam², Syed Fazlul Islam', Mohammad Kamrul Ahsan ${ }^{3}$, S. K. Mamun-Ar-Rashid", \\ Tanvir Rahman ${ }^{5}$, Md. Nazmul Hasan ${ }^{6}$
}

\author{
${ }^{1}$ Department of Nephrology, Bangabandhu Sheikh Mujib Medical University (BSMMU), Dhaka, Bangladesh \\ ${ }^{2}$ Department of Nephrology \& Dialysis, BIRDEM General Hospital, Dhaka, Bangladesh \\ ${ }^{3}$ Holy Family Red Crescent Medical College Hospital (HFRCMCH), Dhaka, Bangladesh \\ ${ }^{4}$ Department of Medicine, Khulna Medical College Hospital, Khulna, Bangladesh \\ ${ }^{5}$ Department of Nephrology, United Hospital Limited, Dhaka, Bangladesh \\ ${ }^{6}$ Department of Cardiology, Ad-din Medical College Hospital, Dhaka, Bangladesh \\ Email: *kabirdrdmc@gmail.com
}

How to cite this paper: Hossain, Md.K., Alam, M.R., Khanam, A., Rahman, A.K.M.S., Islam, R.N., Islam, S.F., Ahsan, M.K., Mamun-Ar-Rashid, S.K., Rahman, T. and Hasan, Md.N. (2020) Incidence, Risk Factors and Short Term Outcome of Acute Kidney Injury among Patients with Acute Coronary Syndrome. Journal of Biosciences and Medicines, 8, 177-188.

https://doi.org/10.4236/jbm.2020.85017

Received: April 11, 2020

Accepted: May 18, 2020

Published: May 21, 2020

Copyright (c) 2020 by author(s) and Scientific Research Publishing Inc. This work is licensed under the Creative Commons Attribution-NonCommercial International License (CC BY-NC 4.0). http://creativecommons.org/licenses/by-nc/4.0/ (c) (i) Open Access

\begin{abstract}
Background: Cardio-renal syndrome is the leading cause of death globally. Acute kidney injury (AKI) is a major complication among patients admitted in Coronary Care Unit (CCU) with acute coronary syndrome (ACS). AKI in ACS patients is associated with higher morbidity, mortality and prolong hospital stay. Objective: To determine the incidence, risk factors and short term outcome of acute kidney injury (AKI) among the patients admitted in CCU with ACS. Methods: This cross sectional study was conducted at Department of Nephrology, Bangabandhu Sheikh Mujib Medical University (BSMMU), Dhaka, Bangladesh from January 2013 to December 2013. Following selection criteria a total of two hundred (200) patients with ACS were studied. AKI was defined according to the KDIGO guideline and further categorized by RIFLE criteria. Data of patients with AKI and those without AKI were analyzed and compared by statistical tests. Results: Majority of the study patients were male (79.5\%). AKI was developed in 40 of the 200 study patients (20.0\%). The mean $( \pm S D)$ age of the study patients was $60.1 \pm 11.1$ years in patients with AKI and $55.9 \pm 10.1$ years in patients without AKI. Our data analysis showed that older age ( $>65$ years), diabetes mellitus, dyslipidemia and smoking were significantly correlated to the development of AKI. Mortality was significantly high in AKI group (7.15\%) compared to no AKI group (1.25\%). Out of $27 \mathrm{pa-}$ tients who achieved renal recovery most $(80.8 \%)$ belonged to risk class. Severity of AKI showed significant effect on renal recovery and final outcome.
\end{abstract}


Conclusion: This study demonstrated that, incidence of AKI among patients with ACS was $20 \%$. Elderly patients, diabetes mellitus, dyslipidemia, and exposure to smoking were significantly associated with development of AKI in ACS.

\section{Keywords}

Acute Kidney Injury (AKI), Acute Coronary Syndrome (ACS), Cardio-Renal Syndrome

\section{Introduction}

Acute kidney injury (AKI) is a major complication in patients with acute coronary syndrome (ACS) and its ultimate expression is the cardio-renal syndrome. It is associated with prolonged hospital stay and higher morbidity and mortality. The prevalence of renal disease was found between $30 \%-60 \%$ in patients with major cardiac events [1]. The incidence of acute kidney injury (AKI) is high (ranging from $10 \%$ to $25 \%$ ) in patients those hospitalized with acute myocardial infarction (AMI) [2]. The development of AKI is associated with unfavorable outcomes and higher mortality after an AMI [2]. Contrast-induced nephropathy may occur up to $25 \%$ of patients undergoing coronary intervention [3] [4]. The occurrence of contrast induced acute kidney injury (CI-AKI) has been associated with poor short and long-term outcomes [4].

Acute coronary syndrome (ACS) may induce AKI through various mechanisms; including impaired cardiac output, use of contrast media in percutaneous coronary intervention (PCI) and the nephrotoxic effect of drugs. It has been suggested that AKI is not only a marker of severity of the illness but is also a causal factor for acceleration of cardiovascular injury through the activation of neurohormonal, immunological and inflammatory pathways [5]. In ACS patients, the most crucial mechanism causing AKI includes hemodynamic changes due to reduced cardiac output, ultimately decreasing glomerular filtration rate (GFR). Of note, factors reflecting cardio-circulatory impairment such as reduced left ventricular ejection fraction, left anterior descending coronary artery lesion and high end-diastolic pulmonary arterial blood pressure are independently associated with AKI in ACS [6]. Furthermore, changes in volume status, medical therapies, athero-embolism (during PCI or intra-aortic balloon pump insertion) and bleeding are involved in the pathogenesis of AKI. Additionally, in ACS patients, enhanced inflammatory response, increased oxidative stress and activation of the sympathetic nervous system synergistically accelerated the development of AKI, causing a vicious cycle amplifying the progression of the ongoing renal injury [7]. Finally, metabolic factors, including acidosis and acute hyperglycemia may favor the development of AKI [8] [9] [10].

The relationship between AKI and short term outcomes remains unclear. Understanding the impact of AKI on short term and long term outcomes will 
have a marked impact on treatment and risk stratification during hospitalization and will assist with guiding follow-up care after discharge from hospital. AKI may serve as a pathogenic factor in the development of other renal sequelae such as proteinuria, hypertension, and chronic kidney disease (CKD), which will compound cardiovascular risk over time. It has been reported that about $13 \%-20 \%$ patients developed AKI after acute coronary syndrome and was associated with increase in hospital morbidity and mortality [11] [12] [13].

In many hospitals, most patients admitted in the CCU with acute coronary syndrome (ACS) are not investigated for renal disease with prime importance. If renal impairment was screened at admission and diagnosed earlier, both cardiac and renal outcomes would be better at discharge of these patients. There is scarce evidence addressing incidence of acute kidney injury, its risk factors and short term outcome among patients with acute coronary syndrome in Bangladesh. Therefore the purpose of the current study was to evaluate the acute kidney injury in patients with acute coronary syndrome admitted in coronary care unit (CCU), BSMMU, Dhaka, Bangladesh. This study could be helpful in estimating the morbidity and mortality of these patients and hence to develop effective preventive strategies to prevent $\mathrm{AKI}$ and thereby reduce the burden of the individual and the society.

\section{Methodology}

This cross sectional study was conducted in Department of Nephrology, Bangabandhu Sheikh Mujib Medical University (BSMMU), Dhaka, Bangladesh form January 2013 to December 2013. This study was approved by the Ethical Review Committee, BSMMU, Dhaka, Bangladesh. Sample size was estimated by using, $n=$ $z^{2} p q / d^{2}$ formula; where allowable error 5\% with 95\% confidence level. Assuming a $20 \%$ prevalence of renal involvement in ACS [2], the required sample size was 245. It was a single centre study and time constraints, therefore a total of $200 \mathrm{pa}-$ tients were studied. Total 200 patients admitted with acute coronary syndrome in coronary care unit (CCU), Department of Cardiology, BSMMU, during the study period were included in this study purposively. Informed written consent was taken from each participant prior to enrollment. Inclusion criteria were adult patients (age $>18$ years) of both sexes with any variety of ACS (Unstable angina, ST elevation MI or non-ST elevation MI). Patient with clinical picture or investigations suggesting chronic kidney disease (CKD), patients undergoing intervention (PCI) and patients with malignancy were excluded from the study.

Participants' demographic profile, clinical examination findings and relevant investigation reports were recorded in a data collection sheet. Each patient was assessed by following investigations-serum creatinine, urine-routine microscopic examination $(\mathrm{R} / \mathrm{M} / \mathrm{E})$, urinary albumin creatinine ratio (ACR), serum electrolytes, complete blood count (CBC), random blood sugar (RBS), ultrasonogram of KUB (kidney ureter and bladder) region, electrocardiography (ECG), electrocardiogram (ECHO-color doppler) and serum Troponin-I level. Patients' serum crea- 
tinine was measured at hospital presentation, everyday during CCU stay and at the time of discharge from hospital. In hospital mortality rate were also recorded. All patients were followed up regularly till their discharge from hospital or death. The study population was divided initially into two groups (AKI group = patient admitted with acute coronary syndrome in CCU developing AKI and No AKI group = patient admitted with acute coronary syndrome in CCU but did not develop AKI) then sub grouped of AKI group into: risk, injury and failure. All AKI cases were categorized in 3 stages/classes based on RIFLE criteria [14]. The differences within outcome variables between the groups were analyzed and compared; these were: age, gender, smoking, diabetes mellitus (DM), hypertension, dyslipidemia, duration of CCU stay and final outcome.

In this study short term outcome of AKI refers to patient outcomes that had occurred during hospital (CCU) stay; these were: partial or complete recovery from AKI or death. On the other hand, long term outcome of AKI refers to the outcomes that developed after discharged from the hospital.

\subsection{Acute Kidney Injury (AKI)}

According to $\mathrm{KDIGO}^{*}$ guideline acute kidney injury is currently defined as an absolute increase in serum creatinine $\geq 0.3 \mathrm{mg} / \mathrm{dl}(\geq 26.4 \mu \mathrm{mol} / \mathrm{l})$, a percentage increase in serum creatinine $\geq 50 \%$ (1.5-fold from baseline), or a reduction in urine output (documented oliguria $<0.5 \mathrm{ml} / \mathrm{kg} /$ hour for $>6$ hours). Or in whom who do not have any previous records, AKI is defined as the increase of serum creatinine by $0.5 \mathrm{mg} / \mathrm{dl}$ and/or by $50 \%$ over baseline, with:

- Previously normal renal function;

- There is no haematuria or proteinuria on routine examination;

- Ultra-sonogram (USG) shows no structural abnormality.

$\left[{ }^{*} \mathrm{KDIGO}=\right.$ Kidney Disease Improving Global Outcomes $]$

\subsection{Different Classifications of Acute Kidney Injury (AKI) [14]}

\section{RIFLE}

an acute $\uparrow$ in $\mathrm{sCr}$ over 7 days

$\begin{array}{ll}\text { Risk } & \uparrow \text { in } \mathrm{sCr} \geq 1.5 \times \text { baseline } \\ \text { Injury } & \uparrow \text { in } \mathrm{sCr} \geq 2.0 \times \text { baseline } \\ \text { Failure } & \uparrow \text { in } \mathrm{sCr} \geq 3.0 \times \text { baseline or } \\ & \uparrow \text { in } \mathrm{sCr} \geq 0.5 \mathrm{mg} / \mathrm{dL} \text { if baseline } \mathrm{sCr} \geq 4.0 \mathrm{mg} / \mathrm{dL} \\ \text { Loss } & \text { Complete loss of kidney function }>4 \text { weeks } \\ \text { ESRD } & \text { End-stage renal disease }>3 \text { months }\end{array}$

AKIN

an acute $\uparrow$ in sCr within $48 \mathrm{~h}$

Stage $1 \quad \uparrow$ in $\mathrm{sCr} \geq 1.5-2.0 \times$ baseline or

$\uparrow$ in $\mathrm{sCr} \geq 0.3 \mathrm{mg} / \mathrm{dL}$ 


\section{Continued}

\begin{tabular}{ll}
\hline Stage 2 & $\uparrow$ in $\mathrm{sCr}>2.0-3.0 \times$ baseline \\
Stage 3 & $\uparrow$ in $\mathrm{sCr}>3.0 \times$ baseline or \\
& $\mathrm{sCr} \geq 4.0 \mathrm{mg} / \mathrm{dL}$ with an acute $\uparrow \geq 0.5 \mathrm{mg} / \mathrm{dL}$ \\
& or initiation of RRT
\end{tabular}

\section{KDIGO}

an acute $\uparrow$ in sCr within $48 \mathrm{~h}$

$\begin{array}{ll}\text { Stage } 1 & \uparrow \text { in } \mathrm{sCr} \geq 1.5-1.9 \times \text { baseline or } \\ & \uparrow \text { in } \mathrm{sCr} \geq 0.3 \mathrm{mg} / \mathrm{dL} \\ \text { Stage 2 } & \uparrow \text { in } \mathrm{sCr} \geq 2.0-2.9 \times \text { baseline } \\ \text { Stage } 3 & \uparrow \text { in } \mathrm{sCr} \geq 3.0 \times \text { baseline or } \\ & \mathrm{sCr} \geq 4.0 \mathrm{mg} / \mathrm{dL} \text { with an acute } \uparrow \geq 0.5 \mathrm{mg} / \mathrm{dL} \\ & \text { or initiation of RRT }\end{array}$

AKIN = acute kidney injury network; ESKD = end-stage kidney disease; KDIGO = Kidney Disease Improving Global Outcomes; RIFLE = Risk, Injury, Failure, Loss, and End-stage renal disease; RRT = renal replacement therapy; $\mathrm{sCr}=$ serum creatinine; $\uparrow=$ increase; $\downarrow=$ decrease

\subsection{Acute Coronary Syndrome (ACS) [15]}

Acute coronary syndrome (ACS) is a syndrome that occurs due to decreased blood flow in the coronary arteries of heart and comprises the following varieties:

\section{ST elevation MI (STEMI):}

- Typical chest pain.

- ECG change: New or presumed new ST-segment elevation at the J point in 2 or more contiguous leads with the cut-off points of $\geq 2 \mathrm{~mm}$ in chest leads (V1-V6) and $\geq 1 \mathrm{~mm}$ in other leads.

- Cardiac marker: raised troponin-I and creatine kinase-MB (CKMB).

\section{Non-ST elevation MI (NSTEMI):}

- Typical chest pain.

- Acute ST depression on the initial ECG.

- Raised cardiac troponin T or I concentration.

Unstable Angina (UA):

It is a clinical syndrome that is characterized by new onset or rapidly worsening angina, angina on minimal exertion or angina at rest.

\subsection{Cardio-Renal Syndrome}

The cardio-renal syndrome (CRS) defined "as an acute worsening of heart function leading to AKI or dysfunction" that is a complication of "acute heart failure and/or acute coronary syndrome (ACS)", associated with a high risk mortality and longer hospital stay [15]. A newly describe syndrome of inter-dependency. Each dysfunctional organ can initiate and maintain disease in the other through common haemodynamic, neurohormonal and immunological pathways.

\subsection{Statistical Analysis}

Data cleaning validation and analysis was performed using the SPSS (Statistical 
Package for Social Science) software. Categorical data were presented as frequency/percentage and continuous variable was expressed as mean \pm SD (standard deviation). The statistics used to analyze the data were descriptive statistics and the tests done were Student's " 2 " test and Chi-square test. The level of significance was set at 0.05 and $p$ value $<0.05$ was considered significant.

\section{Results}

A total of 200 patients with acute coronary syndrome (ACS), who had got admitted in the coronary care unit (CCU), Department of Cardiology, BSMMU were included in this study. The study population was divided initially into two group: AKI group (ACS patients with AKI; $\mathrm{n}=40$, male $=33$, female $=7$ ) and No AKI group (ACS patients without AKI; $\mathrm{n}=160$, male $=126$, female $=34$ ) and AKI group then sub grouped into: risk, injury and failure classes.

Among total 200 ACS patients; AKI was found in 40 (20\%) patients and remaining $160(80 \%)$ patients had no AKI. Incidence of AKI was 20.0\%. Out of 40 (20\%) AKI patients; 26 (13.0\%) were in risk class, 7 (3.5\%) were in injury class and 7 (3.5\%) were in failure class of RIFLE criteria as displaying in Figure 1.

It was observed that among 40 patients of AKI; 20 (50.0\%) patients had ST segment elevated myocardial infarction (STEMI), 19 (47.5\%) patients had non-ST segment elevated myocardial infarction (NSTEMI) and 1 (2.5\%) patient had unstable angina (UA). On the other hand among 160 patients of no AKI group; 83 (51.9\%) patients had ST segment elevated myocardial infarction (STEMI), 64 (40.0\%) patients had non-ST segment elevated myocardial infarction (NSTEMI) and $13(8.1 \%)$ patient had unstable angina (UA). There was no significant difference $(\mathrm{p}=0.386)$ in different types of ACS among the groups (Table 1$)$.

Majority of the study patients were male (79.5\%). Mean $( \pm S D)$ age of the AKI group patients was $60.1 \pm 11.1$ years and patients in no AKI group that was 55.9 \pm 10.1 years. Our data analysis showed that age $>65$ years, duration of CCU stay, diabetes mellitus, dyslipidemia and smoking were significantly correlated to the development of AKI. Mortality was significantly high in AKI group (7.15\%) compared to no AKI group (1.25\%). Other variables did not show any significant association with the development of AKI (Table 2).

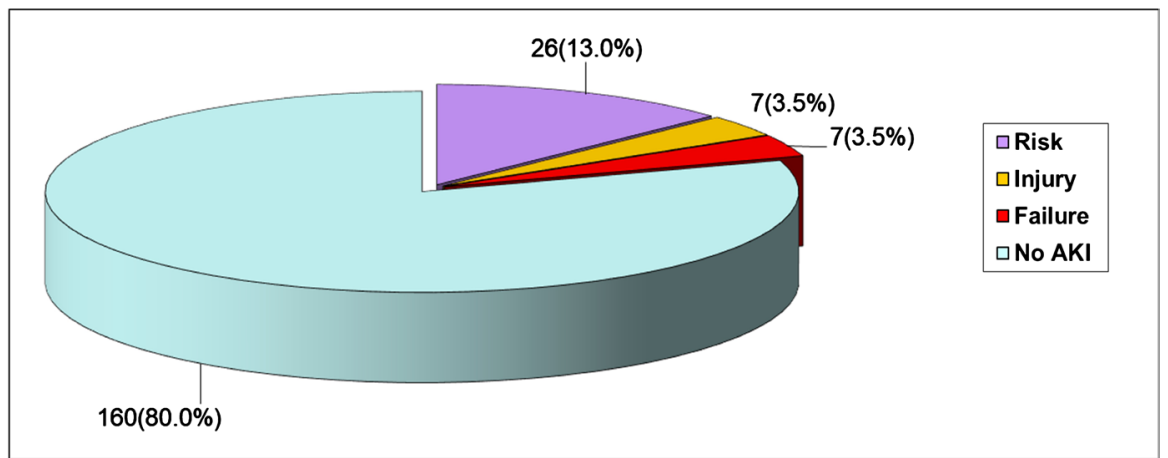

Figure 1. Overall incidence of acute kidney injury (AKI) among acute coronary syndrome (ACS) patients $(n=200)$. 
Table 1. Types of ACS in study patients $(n=200)$.

\begin{tabular}{cccc}
\hline Types of ACS & $\begin{array}{c}\text { AKI }(\mathrm{n}=40) \\
\text { No. (\%) }\end{array}$ & $\begin{array}{c}\text { No AKI }(\mathrm{n}=160) \\
\text { No. (\%) }\end{array}$ & p value \\
\hline NSTEMI & $19(47.5 \%)$ & $64(40.0 \%)$ & \\
STEMI & $20(50.0 \%)$ & $83(51.9 \%)$ & $0.386^{\mathrm{ns}}$ \\
UA & $1(2.5 \%)$ & $13(8.1 \%)$ & \\
\hline
\end{tabular}

Chi-square test was performed to compare between groups. $\mathrm{n}=$ Number of subjects; $\mathrm{ns}=$ Not significant.

Table 2. Risk factors for development of AKI in patients with ACS $(n=200)$.

\begin{tabular}{|c|c|c|c|c|c|}
\hline Parameters & $\begin{array}{c}\text { AKI }(n=40) \\
\text { No. (\%) }\end{array}$ & $\begin{array}{c}\text { No AKI }(\mathrm{n}=160) \\
\text { No. }(\%)\end{array}$ & $p$ value & Odds ratio & $95 \% \mathrm{CI}$ \\
\hline \multicolumn{6}{|l|}{ Age } \\
\hline$<65 \mathrm{yrs}$ & $31(77.50 \%)$ & $139(86.9 \%)$ & \multirow{2}{*}{$0.025^{\star}$} & & \\
\hline$>65 \mathrm{yrs}$ & $9(22.50 \%)$ & $21(13.1 \%)$ & & & \\
\hline Mean \pm SD & $60.1 \pm 11.1$ & $55.9 \pm 10.1$ & & & \\
\hline \multicolumn{6}{|l|}{ Gender } \\
\hline Male & $33(82.50 \%)$ & $126(78.75 \%)$ & 0.599 & 1.272 & $0.518-3.127$ \\
\hline Female & $7(17.50 \%)$ & $34(21.25 \%)$ & & & \\
\hline \multicolumn{6}{|l|}{ Diabetes mellitus } \\
\hline Yes & $25(62.5 \%)$ & $52(32.5 \%)$ & $<0.001^{\star}$ & 3.462 & $1.684-7.115$ \\
\hline No & $15(37.5 \%)$ & $108(67.5 \%)$ & & & \\
\hline \multicolumn{6}{|l|}{ Hypertension } \\
\hline Yes & $28(70.0 \%)$ & $116(72.5 \%)$ & $0.753^{\text {ns }}$ & 0.885 & $0.414-1.893$ \\
\hline No & $12(30.0 \%)$ & $44(27.5 \%)$ & & & \\
\hline \multicolumn{6}{|l|}{ Dyslipidemia } \\
\hline Yes & $16(40.0 \%)$ & $38(23.7 \%)$ & $0.038^{*}$ & 2.14 & $1.032-4.441$ \\
\hline No & $24(60.0 \%)$ & $122(76.3 \%)$ & & & \\
\hline \multicolumn{6}{|l|}{ Smoking } \\
\hline Yes & $22(55.0 \%)$ & $54(33.7 \%)$ & $0.013^{\star}$ & 2.399 & $1.187-4.850$ \\
\hline No & $18(45.0 \%)$ & $106(66.3 \%)$ & & & \\
\hline CCU stay (days) & $10.71 \pm 1.91$ & $5.86 \pm 0.84$ & $<0.001^{\star}$ & & \\
\hline \multicolumn{6}{|l|}{ Final outcome } \\
\hline Survived & 37 (92.5\%) & $158(98.75 \%)$ & $0.02^{\star}$ & 0.16 & $0.02-1.20$ \\
\hline Expired & $3(7.5 \%)$ & $2(1.25 \%)$ & & & \\
\hline
\end{tabular}

Chi-square test for qualitative data and Unpaired $t$-test for quantitative data were performed; $\mathrm{n}=$ Number of subjects; ${ }^{*}=$ Significant; $\mathrm{ns}=$ Not significant.

Among total 40 ACS patients who developed AKI; 26 patients were in risk class, 7 patients were in injury class and 7 patients were in failure class. Out of 27 patients who achieved renal recovery, maximum [21 (80.8\%)] belonged to risk class. An analysis of final outcome revealed that all patients of risk class (26) and injury class (7) were survived while out of 7 patients of failure class 3 patients 
were expired. Among 40 AKI patients; 37 patients were managed conservatively and survived while 3 patients expired despite receiving hemodialysis. Therefore renal recovery, management and mortality were found to be significantly affected by severity of AKI. Besides these, no other variables were found to be significantly correlated with the RIFLE classification of AKI severity (Table 3).

\section{Discussion}

Cardio-renal syndrome is the leading cause of death globally. Acute kidney injury (AKI) has a known catastrophic impact on critically ill patients like acute coronary syndrome (ACS) patients in coronary care unit (CCU) [5] [16]. The relationship between AKI and ACS remains unclear and its pathogenesis is multifactorial. This hospital based study was conducted among 200 patients with ACS to determine the incidence, risk factors and short term outcome of acute kidney injury. Patients with ACS admitted in our coronary care unit and fulfilled the selection criteria were studied.

Table 3. Demographic factors, ACS types and outcomes in relation to AKI severity $(n=40)$.

\begin{tabular}{|c|c|c|c|c|c|}
\hline Parameters & $\begin{array}{c}\text { Risk }(n=26) \\
\text { No. }(\%)\end{array}$ & $\begin{array}{c}\text { Injury }(n=7) \\
\text { No. }(\%)\end{array}$ & $\begin{array}{c}\text { Failure }(n=7) \\
\text { No. }(\%)\end{array}$ & $\begin{array}{c}\text { Total } \\
(n=40)\end{array}$ & $\mathrm{p}$ value \\
\hline \multicolumn{6}{|l|}{ Age } \\
\hline$<65 \mathrm{yrs}$ & $20(76.9 \%)$ & $5(71.4 \%)$ & $6(85.7 \%)$ & 31 & \multirow{2}{*}{$0.571^{\mathrm{ns}}$} \\
\hline$>65 \mathrm{yrs}$ & $6(23.1 \%)$ & $2(28.6 \%)$ & $1(14.3 \%)$ & 9 & \\
\hline Mean \pm SD & $58.69 \pm 12.01$ & $62.42 \pm 9.32$ & $62.85 \pm 9.23$ & & \\
\hline \multicolumn{6}{|l|}{ Gender } \\
\hline Male & $22(84.6 \%)$ & $7(100.0 \%)$ & $4(57.1 \%)$ & 33 & \multirow[t]{2}{*}{$0.09^{\text {ns }}$} \\
\hline Female & $4(15.4 \%)$ & $0(0.0 \%)$ & $3(42.9 \%)$ & 7 & \\
\hline \multicolumn{6}{|l|}{ Types of ACS } \\
\hline NSTEMI & $11(42.3 \%)$ & $4(57.1 \%)$ & $4(57.1 \%)$ & 19 & \multirow{2}{*}{$0.88^{\mathrm{ns}}$} \\
\hline STEMI & $14(53.8 \%)$ & $3(42.9 \%)$ & $3(42.9 \%)$ & 20 & \\
\hline UA & $1(3.8 \%)$ & $0(0.0 \%)$ & $0(0.0 \%)$ & 1 & \\
\hline CCU stay (days) & $9.85 \pm 1.22$ & $10.57 \pm 0.98$ & $11.71 \pm 3.55$ & & $0.06^{\mathrm{ns}}$ \\
\hline \multicolumn{6}{|l|}{ Renal recovery } \\
\hline Yes & $21(80.8 \%)$ & $3(42.9 \%)$ & $3(42.9 \%)$ & 27 & \multirow[t]{2}{*}{$0.05^{\star}$} \\
\hline No & $5(19.2 \%)$ & $4(57.1 \%)$ & $4(57.1 \%)$ & 13 & \\
\hline \multicolumn{6}{|l|}{ Final outcome } \\
\hline Survived & $26(100.0 \%)$ & $7(100.0 \%)$ & $4(57.1 \%)$ & 37 & \multirow[t]{2}{*}{$<0.001^{\star}$} \\
\hline Expired & $0(0.0 \%)$ & $0(0.0 \%)$ & $3(42.9 \%)$ & 3 & \\
\hline \multicolumn{6}{|l|}{ Management } \\
\hline Conservative & $26(100.0 \%)$ & $7(100.0 \%)$ & $4(57.1 \%)$ & 37 & \multirow[t]{2}{*}{$<0.001^{\star}$} \\
\hline Hemodialysis & $0(0.0 \%)$ & $0(0.0 \%)$ & $3(42.9 \%)$ & 3 & \\
\hline
\end{tabular}

Chi-square test for qualitative data and unpaired $t$-test for quantitative data were performed. $\mathrm{n}=$ Number of subjects; ${ }^{*}=$ Significant; $n s=$ Not significant. 
The study population was divided initially into two groups (AKI group and No AKI group) then sub grouped into risk, injury and failure classes according to the severity of renal impairment. In our study AKI occurred in 40 of the 200 ACS patients during their CCU stay. Therefore the overall incidence of AKI in ACS patients was $20.0 \%$, which was consistent with other studies as reported that prevalence of AKI among patients admitted with acute coronary syndrome in CCUs was $13 \%$ - 20\% [1] [2] [13]. The mean age of the study patients in AKI group was $60.1 \pm 11.1$ years, while in no AKI group that was $55.9 \pm 10.1$ years. The mean age difference between two groups was found statistically significant $(\mathrm{p}=0.025)$ and this finding was accordant with a previous study which showed that ACS patients with AKI were older (61.6 \pm 15 years) than the non-AKI group ( $54.7 \pm 13$ years, $\mathrm{p}=0.031)$ [17]. It was found that; in AKI group $82.50 \%$ patients were male and $17.50 \%$ were female, while in no AKI group $78.75 \%$ were male and $21.25 \%$ were female patients. Among total study population majority of the patients were male (79.5\%). Similar findings were observed in previous studies [15] [17]. Mean $( \pm S D)$ duration of CCU stay was significantly higher $(\mathrm{p}<0.001)$ among patients with AKI (10.71 \pm 1.91 days) compared to patients without AKI (5.86 \pm 0.84 days) and this was also a finding in the previous study as well [17].

Patients with no AKI (98.75\%) had significantly higher ( $p=0.02)$ chance of survival compared to patients with AKI (92.5\%). In accordance Buargub M and Elmokhtar ZO reported that the CCU mortality among the AKI patients was $25.7 \%$ compared with $6.12 \%$ in the non-AKI patients, and the mortality worsened with increasing severity of AKI [17].

The risk of developing AKI was significantly high in patients associated with diabetes mellitus $(\mathrm{p}<0.001)$, dyslipidemia $(\mathrm{p}=0.038)$ and smoking $(\mathrm{p}=0.013)$ while there was no significant association in patients with hypertension $(\mathrm{p}=$ 0.753). These results were statistically significant and supported by a few previous studies [18] [19].

In this study, out of 40 patients who had developed AKI 37 (92.5\%) survived; while out of 160 patients who did not developed AKI 158 (98.75\%) survived. AKI severity had significant effect $(\mathrm{p}=0.05)$ on renal recovery. Out of $27 \mathrm{pa}-$ tients who achieved renal recovery, 21 (77.8\%) belonged to the "risk" class, followed by the "injury" 3 (11.1\%) and "failure" 3 (11.1\%) classes. Out of 37 patients who survived, $26(70.3 \%)$ allocated to "risk", 7 (18.9\%) to "injury" and 4 (10.8\%) to "failure" classes of the RIFLE classification of AKI severity. It was observed that although $5(19.2 \%)$ patients with mild renal impairment (i.e. the risk class) and 4 (57.1\%) of those with moderate renal impairment (i.e. the injury class) did not fully regain their previously normal renal function; all of the patients in these two groups survived and received conservative management. The 3 (42.9\%) patients who expired belonged to only the "failure" class and none of their renal functional parameters improved despite hemodialysis. Within this class, the other patients were managed conservatively and among the 4 (57.1\%) patients who survived, 3 (42.9\%) had AKI (resolved) and 1 (14.2\%) was dis- 
charged with renal functional impairment possibly leading to CKD. The final outcome was thus found to be significantly influenced $(p<0.001)$ by the severity of AKI. These findings were consistent with previous studies as reported that ACS patients with AKI compared to non-AKI patients demonstrated greater risk of poorer outcomes [20] [21].

AKI was detected in $20 \%$ of ACS cases among total 200 CCU patients which was most often hospital acquired and probably due to hemodynamic causes. Despite much progress and increased recognition of AKI, it still remains an underestimated and unnoticed entity in patients with ACS. Although there is a high mortality rate in these patients, there were a significant number of survivors. In this study we aimed to provide a framework of knowledge to increase physicians' awareness of AKI among patients with ACS, with the goal of improving the outcome of these patients.

\section{Conclusion}

This study demonstrated that, incidence of AKI after ACS was $20 \%$. We conclude that elderly patient, diabetes mellitus, dyslipidemia, exposure to smoking were significantly associated with development of AKI in ACS. Morbidity and mortality were significantly high in AKI compared to no AKI group among patients with ACS. Appropriate intervention in early stages of AKI may have a positive impact on patient outcomes.

\section{Limitations of Study}

It was a single centre study with a relatively small sample size.

\section{Recommendations}

Acute kidney injury (AKI) has a known catastrophic impact on critically ill patients. Morbidity and mortality are significantly high in AKI patients with ACS. A large scale, multi-center study will be needed to assess the long term survival of these patients.

\section{Conflicts of Interest}

The authors declare no conflicts of interest regarding the publication of this paper.

\section{References}

[1] Ezekowitz, J., McAlister, F.A., Humphries, K.H., Norris, C.M., Tonelli, M., Ghali, W.A., Knudtson, M.L. and APPROACH Investigators (2004) The Association among Renal Insufficiency, Pharmacotherapy, and Outcomes in 6,427 Patients with Heart Failure and Coronary Artery Disease. Journal of the American College of Cardiology, 44, 1587-1592. https://doi.org/10.1016/j.jacc.2004.06.072

[2] Liano, F., Junco, E., Madero, R., Pascual, J. and Verde, E. (1998) The Spectrum of Acute Renal Failure in the Intensive Care Unit Compared with That Seen in Other Settings. Kidney International Supplements, 66, 16-24. 
[3] Goldenberg, I., Chonchol, M. and Guetta, V. (2009) Reversible Acute Kidney Injury Following Contrast Exposure and the Risk of Long-Term Mortality. American Journal of Nephrology, 29, 136-144. https://doi.org/10.1159/000151772

[4] Mehran, R., Aymong, E.D., Nikolsky, E., Lasic, Z., Iakovou, I., Fahy, M., Mintz, G.S., Lansky, A.J., Moses, J.W., Stone, G.W. and Leon, M.B. (2004) A Simple Risk Score for Prediction of Contrast-Induced Nephropathy after Percutaneous Coronary Intervention: Development and Initial Validation. Journal of the American College of Cardiology, 44, 1393-1399. https://doi.org/10.1016/S0735-1097(04)01445-7

[5] Ronco, C., Haapio, M., House, A.A., Anavekar, N. and Bellomo, R. (2008) Cardiorenal Syndrome. Journal of the American College of Cardiology, 52, 1527-1539. https://doi.org/10.1016/j.jacc.2008.07.051

[6] Senoo, T., Motohiro, M., Kamihata, H., Yamamoto, S., Isono, T., Manabe, K., Sakuma, T., Yoshida, S., Sutani, Y. and Iwasaka, T. (2010) Contrast-Induced Nephropathy in Patients Undergoing Emergency Percutaneous Coronary Intervention for Acute Coronary Syndrome. The American Journal of Cardiology, 105, 624-628. https://doi.org/10.1016/j.amjcard.2009.10.044

[7] Anzai, A., Anzai, T., Naito, K., Kaneko, H., Mano, Y., Jo, Y., Nagatomo, Y., Maekawa, Y., Kawamura, A., Yoshikawa, T. and Ogawa, S. (2010) Prognostic Significance of Acute Kidney Injury after Reperfused ST-Elevation Myocardial Infarction: Synergistic Acceleration of Renal Dysfunction and Left Ventricular Remodeling. Journal of Cardiac Failure, 16, 381-389. https://doi.org/10.1016/j.cardfail.2009.12.020

[8] Stolker, J.M., McCullough, P.A., Rao, S., Inzucchi, S.E., Spertus, J.A., Maddox, T.M., Masoudi, F.A., Xiao, L. and Kosiborod, M. (2010) Pre-Procedural Glucose Levels and the Risk for Contrast-Induced Acute Kidney Injury in Patients Undergoing Coronary Angiography. Journal of the American College of Cardiology, 55, 1433-1440. https://doi.org/10.1016/j.jacc.2009.09.072

[9] Van den Berghe, G., Wilmer, A., Hermans, G., Meersseman, W., Wouters, P.J., Milants, I., Van Wijngaerden, E., Bobbaers, H. and Bouillon, R. (2006) Intensive Insulin Therapy in the Medical ICU. New England Journal of Medicine, 354, 449-461. https://doi.org/10.1056/NEJMoa052521

[10] Marenzi, G., De Metrio, M., Rubino, M., Lauri, G., Cavallero, A., Assanelli, E., Grazi, M., Moltrasio, M., Marana, I., Campodonico, J. and Discacciati, A. (2010) Acute Hyperglycemia and Contrast-Induced Nephropathy in Primary Percutaneous Coronary Intervention. American Heart Journal, 160, 1170-1177. https://doi.org/10.1016/j.ahj.2010.09.022

[11] Marenzi, G., Cabiati, A., Bertoli, S., Assanelli, E., Marana, I., De Metrio, M., Rubino, M., Grazi, M., Moltrasio, M. and Lauri, G. (2012) Clinical and Prognostic Relevance of Serum Creatinine Changes in Acute Coronary Syndromes. European Heart Journal, 33, 205-205.

[12] Behrend, T. and Miller, S.B. (1999) Acute Renal Failure in the Cardiac Care Unit: Etiologies, Outcomes, and Prognostic Factors. Kidney International, 56, 238-243. https://doi.org/10.1046/j.1523-1755.1999.00522.x

[13] Marenzi, G., Cabiati, A., Bertoli, S., Assanelli, E., Lauri, G., Marana, I., De Metrio, M., Rubino, M., Campodonico, J. and Grazi, M. (2011) Clinical and Prognostic Relevance of Acute Kidney Injury in Patients with Acute Coronary Syndromes. European Heart Journal, 32, 187-187.

[14] Cosentino, N., Milazzo, V., Campodonico, J. and Marenzi, G. (2017) Acute Kidney Injury in Patients with ST-Elevation Myocardial Infarction. Journal of Heart and Stroke, 2, 1020. 
[15] Ortega-Hernández, J., Springall, R., Sánchez-Muñoz, F., Arana-Martinez, J.C., González-Pacheco, H. and Bojalil, R. (2017) Acute Coronary Syndrome and Acute Kidney Injury: Role of Inflammation in Worsening Renal Function. BMC Cardiovascular Disorders, 17, 202. https://doi.org/10.1186/s12872-017-0640-0

[16] Shlipak, M.G., Heidenreich, P.A., Noguchi, H., Chertow, G.M., Browner, W.S. and McClellan, M.B. (2002) Association of Renal Insufficiency with Treatment and Outcomes after Myocardial Infarction in Elderly Patients. Annals of Internal Medicine, 137, 555-562. https://doi.org/10.7326/0003-4819-137-7-200210010-00006

[17] Buargub, M. and Elmokhtar, Z.O. (2016) Incidence and Mortality of Acute Kidney Injury in Patients with Acute Coronary Syndrome: A Retrospective Study from a Single Coronary Care Unit. Saudi Journal of Kidney Diseases and Transplantation, 27, 752. https://doi.org/10.4103/1319-2442.185238

[18] Sørensen, C.R., Brendorp, B., Rask-Madsen, C., Køber, L., Kjøller, E. and Torp-Pedersen, C. (2002) The Prognostic Importance of Creatinine Clearance after Acute Myocardial Infarction. European Heart Journal, 23, 948-952. https://doi.org/10.1053/euhj.2001.2989

[19] Wright, R.S., Reeder, G.S., Herzog, C.A., Albright, R.C., Williams, B.A., Dvorak, D.L., Miller, W.L., Murphy, J.G., Kopecky, S.L. and Jaffe, A.S. (2002) Acute Myocardial Infarction and Renal Dysfunction: A High-Risk Combination. Annals of Internal Medicine, 137, 563-570. https://doi.org/10.7326/0003-4819-137-7-200210010-00007

[20] Chandrasekhar, J., Baber, U., Sartori, S., Mehran, R., Dangas, G., Kovacic, J., Moreno, P., Vogel, B., Sorrentino, S., Farhan, S. and Faggioni, M. (2017) Trends in Incidence and Mortality Associated with Acute Kidney Injury in Patients Undergoing PCI for Acute Coronary Syndrome. Journal of the American College of Cardiology, 69, 1204. https://doi.org/10.1016/S0735-1097(17)34593-X

[21] Rodrigues, F.B., Bruetto, R.G., Torres, U.S., Otaviano, A.P., Zanetta, D.M. and Burdmann, E.A. (2010) Effect of Kidney Disease on Acute Coronary Syndrome. Clinical Journal of the American Society of Nephrology, 5, 1530-1536.

https://doi.org/10.2215/CJN.01260210 